\title{
Triazoles as a class of multifunctional corrosion inhibitors. Review. Part III. 1,2,3-Benzotriazole and its derivatives. Aluminum alloys
}

\author{
Yu.I. Kuznetsov \\ A.N. Frumkin Institute of Physical Chemistry and Electrochemistry, Russian Academy of \\ Sciences, Leninsky pr. 31, 119071 Moscow, Russian Federation \\ E-mail: kuznetsov@ips.rssi.ru
}

\begin{abstract}
This article continues the review of studies (mainly for 2005-2020) on 1,2,3-benzotriazole (BTA) and its derivatives as corrosion inhibitors (CIs) of various metals from aqueous solutions in a wide $\mathrm{pH}$ range. However, only studies on the effect of these organic CIs on the corrosion and electrochemical behavior of aluminum and mainly its alloys are covered here. In contrast to the previously considered metals protected by these $\mathrm{CIs}(\mathrm{Cu}, \mathrm{Zn}, \mathrm{Fe})$, their alloys and steels, the protective layers formed by BTA and its derivatives are generally not due to hardly soluble complex compounds with the cations of the base metal. In addition to the adsorption of benzotriazoles on aluminum alloys, their ability to block copper and copper-containing intermetallics, which can initiate local corrosion of aluminum itself, plays an important role. The ability of BTA to enhance the protection of aluminum alloys in neutral solutions with other CIs is noted. BTA and its substituted derivatives can be very useful in obtaining protective conversion coatings on copper-containing aluminum alloys. Since direct incorporation of CI into coatings can cause their undesirable chemical interaction with the binder and other process additives, BTA and its derivatives can first be incorporated into nano- or microcontainers made of a neutral material, and only then such containers are incorporated into paints or other protective coating materials. A brief analysis of the advantages of such coatings containing encapsulated BTA or its substituted derivatives is given. Examples of their use in protective coatings, often called self-healing or "smart" coatings, are given. Although the ability of BTA and its derivatives to slow down acid corrosion of aluminum alloys has been little studied, it has been found that they mainly slow down the cathodic reaction, and incorporation of a substituent into position 5 of BTA enhances its inhibitory properties in hydrochloric acid solutions.
\end{abstract}

Keywords: corrosion inhibitors, 1,2,3-benzotriazole, aluminum alloys, conversion coatings, nanocontainers, microcontainers.

Received: August 13, 2020. Published: September 29, 2020

doi: $\underline{10.17675 / 2305-6894-2020-9-4-1}$

\section{Introduction}

Aluminum is the most abundant metal on Earth (according to various estimates, its content in the earth's crust is estimated to be no less than 7.5\%). This metal has valuable properties. Its lightness, strength, high electrical and thermal conductivity are especially valuable, 
therefore, its alloys are widely used in various fields of industry and construction, energy, aircraft and automotive industry [1,2].

Aluminum and its alloys have a high affinity for oxygen; therefore, in the air, their surface is covered with a compact oxide film, but due to the amphoteric nature of the base metal, it dissolves in alkaline $(\mathrm{pH} \geq 9)$ and acid $(\mathrm{pH}<5)$ media. However, this oxide film undergoes pitting corrosion even in neutral media containing corrosive chloride anions. There are a number of methods to combat the corrosion of aluminum alloys. One of these involves the use of corrosion inhibitors (CIs), including organic ones [3-6]. A prominent place among them belongs to heterocyclic compounds that contain oxygen, sulfur and/or nitrogen that often directly interact with the surface of metals to form physical (ionic) or chemisorption bonds. The efficiency of such CIs depends on their chemical structure that determines the adsorption ability and possibility to form thin films of insoluble complex compounds with cations of the metal being protected. In turn, the nature and charge of the metal surface play an important role in its interaction with organic CIs, and therefore in the efficiency of protection.

Triazoles are among the most common azole-type CIs of metals, and 1,2,3benzotriazole (BTA) and its substituted derivatives continue to be studied and widely used in practice for more than 50 years [7-15]. Such interest in BTA and substituted BTAs is due to their ability not only to be chemisorbed on copper, zinc, and their alloys under certain conditions, but also form thin protective films of complex compounds with cations of these metals. This is reflected in many review articles [4, 8-10]. Besides, BTA and some of its substituted derivatives are volatile compounds that are often added to many volatile CIs $[4,11-13]$, and have recently been tested as a new type of vapour phase CIs chamber inhibitors (ChIn) [14].

A little later, BTA and its derivatives aroused interest as CIs of iron and various steels, since the formation of complex compounds with iron cations by these compounds was not as obvious as in the case of copper or zinc. However, it was found that in many environments, BTA or its derivatives, for example, 5-chloro-BTA, can be strongly chemisorbed on steels and are well compatible with other efficient CIs for ferrous metals. Moreover, they are, at least, no less efficient than many traditional CIs in such important areas as the protection of steel products from atmospheric corrosion, steel reinforcement in concrete, etc. $[4,15,16]$.

In this connection, it seems interesting to consider the possibility of using BTA and its substituted derivatives for the protection of light metals and alloys, primarily aluminum and its alloys. Although the author of this review is well aware that the capabilities of these CIs are not as wide as in the case of copper protection and even steel, it would be wrong to neglect the analysis of the already known works, among which there are many positive results. 


\section{Aluminum and its alloys}

\section{Neutral environments}

As with the protection of iron or steel, the results of the first studies on the corrosion inhibition of aluminum alloys with BTA did not look so optimistic. For example BTA was studied as an alternative to chromates in the protection of the 2014-16 aviation aluminum alloy with the composition (mass \%): $4.2 \mathrm{Cu} ; 0.74 \mathrm{Si} ; 0.56 \mathrm{Mg} ; 0.4 \mathrm{Mn} ; 0.29 \mathrm{Fe}$, in a solution of $0.6 \mathrm{M} \mathrm{NaCl}$ at $C_{\mathrm{in}}=2 \mathrm{mM}$ [17]. However, the degree of protection of the alloy from corrosion $(Z, \%)$ by molybdate, nitrate, 2-mercaptobenzothiazole (2-MBT) or 2-mercaptopropyrimidine was more than 2 times higher than by BTA.

Trabanelli et al. [18] studied the ability of several organic CIs, including BTA, benzimidazole (BIA), 2-mercapto-BI (2-MBI) and 2-MBT to prevent pitting on AA 6351 alloy in 0.01 and $0.1 \mathrm{M} \mathrm{NaCl}$ at $t=30^{\circ} \mathrm{C}$. They found that even in a dilute chloride solution, 2-MBT and 2-MBI are superior to BTA in efficiency, while only 2-MBT prevents pitting in 0.1 M solution.

However, in a study of three organic CIs of aluminum alloy 6063 in a deaerated carbonate solution, it was shown [19] that BTA could slow down both electrode reactions better than thiourea, although it was inferior to di-ortho-aminodiphenyl-disulfane.

Zheludkevich, Ferreira et al. [20] studied the effect of 1,2,4-triazole (AT), 3-amino1,2,4-triazole (ATA), BTA, and 2-MBT on the corrosion of aluminum alloy 2024 containing $3.8-4.9 \% \mathrm{Cu}, 1.2-1.8 \% \mathrm{Mg}, 0.5 \% \mathrm{Si}, 0.5 \% \mathrm{Fe}$ in a neutral $0.05 \% \mathrm{NaCl}$ solution. These organic compounds were found to be CIs that formed thin protective layers on the alloy surface. All triazoles were studied at $C_{\mathrm{in}}=3.5 \mathrm{~g} / \mathrm{L}$, but the concentration of MBT was as low as $0.6 \mathrm{~g} / \mathrm{L}$ due to its low solubility in a neutral solution. However, for ATA it had to be increased to $15 \mathrm{~g} / \mathrm{L}$ because its protective effect was very small. The efficiency of corrosion inhibition by these compounds was studied by recording polarization curves that indicated their ability to slow down both the anodic and cathodic reactions. It is significant that the cathodic oxygen reduction reaction that predominantly occurs on intermetallic particles of the alloy was also hindered. 2-MBT, despite its lower $C_{\text {in }}$, as well as BTA showed a better protection efficiency for the alloy than 1,2,4-triazole and ATA. EIS studies also confirmed the advantages of BTA and 2-MBT not only in preserving the aluminum oxide film on the alloy but also in a higher polarization resistance of the alloy in the presence of these CIs. Kelvin scanning probe microscopy and atomic force microscopy (ACM) were used to study the distribution of the Volta potential and surface topography during the corrosion tests.

The protective properties of BTA on aluminum alloy 1050, low carbon steel, and copper were studied [21] in a solution of $3.5 \% \mathrm{NaCl}$ by measuring the weight loss of the samples and recording EIS spectra and anodic polarization curves. It was concluded that, in contrast to chemisorption on copper, BTA is adsorbed more weakly on steel and aluminum alloy by the mechanism of predominant physical interaction of the CI with the surface. It is not surprising that the stability of the protective layers formed by BTA on the surfaces of various metals decreases in the series: copper > mild steel > aluminum alloy 1050 . 
Later, it was suggested to use BTA and tolyltriazole (TTA) as alternatives to toxic chromates, however not independently but in combinations with organosilanes. For example, BTA or TTA were added, along with cerium salts, to improve the characteristics of silane films obtained by pretreatment of the surface of aluminum alloy AA 2024-T3 [22]. To understand the mechanism of action of these additives, it was first shown that each of these additives could slow down the cathodic and anodic reactions on the alloy under study at $C_{\text {in }}=100-1000 \mathrm{mg} / \mathrm{L}$ in $0.5 \mathrm{M} \mathrm{NaCl}$. After that, the effect of adding the CIs to silane films was studied and it was shown that they were slowly extracted from such films, thus improving the corrosion protection of the alloy. Besides, cerium nitrate showed the capability of self-healing silane protective films after scratches were artificially made in the coating.

The reason for the protective action of BTA in chloride and sulfate-containing environments on AA 2024 alloy that is widely used in aviation is due to the presence of copper in this alloy, to which sulfates and chlorides are very corrosive. In view of this, it is logical to assume that the inhibition of local corrosion of AA 2024 alloy, i.e., pitting, in such environments can be based on blocking the intermetallic compounds of copper.

To study the specific features of the protection of AA 2024-T3 aluminum alloy with BTA, electrochemical noise measurements and observation of the alloy surface by scanning electron microscopy (SEM) in sulfate-containing chloride solutions were used [23]. During the study, the concentration of sulfate ions was maintained at $0.1 \mathrm{M}$, and the concentration of chlorides was varied to assess the effect of BTA on the general and local corrosion of the alloy. At $C_{\mathrm{Cl}^{-}}=0.5 \mathrm{M}$, pure aluminum electrodes (99.999\%) were also studied to compare the effect of BTA on the general corrosion of the aluminum matrix and AA-2024 particles rich with copper.

At high $C_{\mathrm{Cl}^{-}}$, BTA prevents uniform corrosion of the alloy by blocking the particles rich with copper. This was shown by a decrease in the amplitude of potential and current fluctuations after the addition of BTA, as well as by the SEM image. In contrast, the inhibitory effect of BTA cannot be controlled by noise resistance $R_{\mathrm{n}}$ and noise impedance $Z_{\mathrm{n}}$ at $0.01 \mathrm{~Hz}$, which is equal to the impedance $Z$ of the electrode at this frequency. These two values did not change when BTA was added to the corrosive solution, since fluctuations in potential and current are provoked by local corrosion, while $R_{\mathrm{n}}$ and $Z$ correspond to the averaged corrosion behavior of the electrode.

At low $C_{\mathrm{Cl}^{-}}=0.01$ or $0.001 \mathrm{M} \mathrm{NaCl}$, BTA efficiently protects the metal from local corrosion, which could be detected in a solution without BTA by $R_{\mathrm{n}}$ values lower than $Z_{\mathrm{n}}=Z$ at $0.01 \mathrm{~Hz}$.

Another well-known method - scanning vibrating electrode (SVET) - was used by Williams et al. [24] for quantification of the effect of several reagents that form complexes with copper on the pitting corrosion kinetics of AA 2024-T3 alloy immersed in aqueous 5\% $\mathrm{NaCl}$ solution. It was shown that organic anions of compounds such as BTA, 2,5dimercapto-1,3,4-thiadiazole (DMTD), N,N-diethyldithiocarbamate (DEDTC), and 
inorganic ions (ferrocyanide) efficiently suppress pitting corrosion. They form protective films on intermetallic particles with a high copper content and/or precipitated aqueous copper cations. In this case, BTA was more efficient than ferrocyanide, but inferior to $\mathrm{DMTD} \approx$ DEDTC. In contrast, the presence of ethylenediaminetetraacetic acid (EDTA) does not reduce local corrosion currents, though it forms soluble copper complexes. It was concluded that the cathodic activity of intermetallic inclusions with a high copper content could be maintained even in the absence of copper deposition, to maintain stable ulceration of the AA 2024 alloy.

The degree of protection, $Z \%=\left[\left(K_{\mathrm{bg}}-K_{\mathrm{in}}\right) / K_{\mathrm{bg}}\right] \cdot 100 \%$, of two aluminum alloys AA2024 and AA7075 (wt.\%: $\mathrm{Cu} 1.4, \mathrm{Mg} 2.4, \mathrm{Mn}<0.1, \mathrm{Fe} 0.2, \mathrm{Zn} 5.4$ ) in $0.10 \mathrm{M} \mathrm{NaCl}$ solution by 28 organic CIs with various chemical structures was determined [25]. The results of four-week tests at $C_{\text {in }}=1 \mathrm{mM}$ were compared with chromate, which provided complete protection of both alloys under these conditions. It was found that BTA, although it was slightly inferior to chromate in the protective effect, was the best organic CI for AA 2040 alloy $(Z=98 \%)$. In the protection of AA AA7575 alloy, BTA ranks third (after sodium diethyldithiocarbamate with $Z=97 \%$ and 6-amino-2-MBT with $Z=94 \%$ ), providing $Z=92 \%$.

It better protects the AA 2040 alloy than A7075, which is not surprising, since the former contains three times more copper than the latter, and the main function of this CI is to block intermetallide particles rich with copper.

One of the advantages of BTA as a CI in neutral environments is its ability to enhance the protection of metals in combination with other CIs. We already noted this property of BTA in the protection of not only copper but also low-carbon steel $[11,16]$, but it can also be observed in the protection of aluminum alloys. In view of this, the work by S. Marcelin and N. Peber [26] who studied the corrosion protection of aluminum alloy 2024 with two efficient CIs, 8-hydroxyquinoline (8-HQ) and BTA, is noteworthy. Knowing that the corrosion of this alloy occurs mainly due to local contacts between the aluminum matrix and copper-rich intermetallic particles, they used, in addition to traditional electrochemical studies of the alloy, an ingenious method for local EIS measurement. To do so, they used a system consisting of the pure $\mathrm{Al}(99.9999 \mathrm{wt} . \%)$ /pure copper $\mathrm{Cu}(99.9 \mathrm{wt} \%$ ) couple. The electrode was prepared as follows: a hole was drilled in the center of an aluminum cylinder with $\varnothing 2.0 \mathrm{~cm}$, into which a copper cylinder with $\varnothing 0.63 \mathrm{~cm}$ was inserted by force. Then, the electrode was mounted into epoxy resin. Before immersion into the electrolyte, the disk electrode of aluminum and copper was prepared like the rods of AA 2024 or pure aluminum and copper.

As a corrosive medium, a solution of $1 \mathrm{M} \mathrm{Na}_{2} \mathrm{SO}_{4}$ prepared from deionized water was used, to which $0.05 \mathrm{M} \mathrm{NaCl}$ was added. Sodium sulfate was used to improve the conductivity of the solution and because of its low corrosiveness to the aluminum alloy. Dilute solutions were used for local impedance experiments: $10^{-3} \mathrm{M} \mathrm{NaCl}, 10^{-2} \mathrm{MBTA}, 3 \cdot 10^{-3} \mathrm{M} 8$-HQ or $10^{-2}$ MBTA $+3 \cdot 10^{-3}$ M 8-HQ. Such CI concentrations were chosen because of the proximity 
to their solubility limits in the neutral solution, which allowed the highest efficiency of BTA and 8-HQ themselves tested separately to be reached.

From the results of electrochemical measurements, it was concluded that the mixture of 8-HQ and BTA provides synergistic protection of AA 2024 alloy. In this case, different protection mechanisms of BTA and 8-HQ were revealed: BTA mainly reduces the activity of intermetallic particles rich with copper, whereas 8-HQ slows down the dissolution of the aluminum matrix since it forms sparingly soluble complex compounds with aluminum. It is also important that in the presence of both CIs, the "galvanic coupling" responsible for corrosion is very limited, which does not occur when CIs are used separately. This conclusion was confirmed by surface observations using SEM.

The corrosion inhibition of AA2040-T3 alloy with 8-HQ, BTA, and 2-MBT was also studied in a more corrosive $3.5 \% \mathrm{NaCl}$ solution [27]. The efficiency of each CI was evaluated by analysis of electrochemical noise, EIS, potentiodynamic polarization of the electrode and the divided cells method. It was concluded that 2-MBT has better protective properties in the concentrated chloride solution than 8-HQ and BTA. In fact, alloy samples immersed in such a solution with addition of 2-MBT showed high values of noise resistance, which persisted for more than 400 hours of testing, and high values of low-frequency resistance remained even after immersion for 24 hours. The method of divided cells and potentiodynamic polarization curves showed that only 2-MBT significantly reduces the rate of both anodic and cathodic reactions. SEM observations and energy dispersive X-ray (EDX) measurements supplementing the results of electrochemical measurements indicate that only 2-MBT protects particles of the second phase, preventing stratification and the onset of corrosion. In contrast to the relatively dilute chloride solutions studied in the work cited above, another study [26] did not reveal a slowdown of the cathodic reaction in the presence of BTA. It inhibits only the anodic dissolution of the alloy, whereas 8-HQ almost does not change the kinetics of either reaction.

In [28], the effect of BTA and cerium chloride $\left(\mathrm{CeCl}_{3}\right)$ on the electrochemical behavior of the $\mathrm{Al} / \mathrm{Cu}$ couple in neutral aerated $\mathrm{NaCl}$ solutions separately and their combination was evaluated. A synergism of their joint use was revealed, which provided permanent protection against corrosion after 46 hours of immersion of an $\mathrm{Al} / \mathrm{Cu}$ couple in a chloride solution. The $\mathrm{Al} / \mathrm{Cu}$ galvanic couple model was analyzed by the SVET method. Additional methods, such as UV spectrophotometry and time-of-flight secondary ion mass spectrometry (ToF-SIMS), were used, respectively, to study the decomposition of BTA molecules and to confirm the chemical composition of the combined layer based on BTA and cerium. Note that earlier Ferreira et al. [29] found a synergy of the protective action of BTA with cerium nitrate during corrosion inhibition of other galvanically coupled metals: Fe and $\mathrm{Zn}$. They were the first to use a microelectrode matrix cell using the SVET method to quantitatively measure the current of the galvanic couple. Their results showed excellent prospects of combining these CIs for efficient corrosion suppression if the mechanisms of inhibition by each of them are different. This is especially interesting since a combination of the two CIs does not show synergism in protecting individual, i.e., unbound metals of the galvanic couple. 
In the next work by Coelho et al. [30], the study of the effect of BTA and $\mathrm{CeCl}_{3}$ on the electrochemical behavior of AA 2024-T3 alloy in $0.05 \mathrm{M} \mathrm{NaCl}$ was supplemented by the EIS method. Analysis of the results obtained with a longer immersion of the alloy in the solution confirmed that the synergistic effect of the CI mixture is also observed after 14 days of immersion of the electrode in the solution. The SVET method was also applied to the $\mathrm{Al} / \mathrm{Cu}$ galvanic couple model to better understand the effect of CIs. Analysis of its results showed that the formation of the CuBTA complex suggests the presence of $\mathrm{Cu}$ ions in the solution. In the case of alloys, the mechanisms of the processes occurring around intermetallic inclusions can form a CuBTA protective layer due to generation of $\mathrm{Cu}$ ions.

An EIS study of AA2024 alloy in a solution containing $\mathrm{CeCl}_{3}$ showed that increasing $C_{\text {in }}$ is not always useful for protecting this alloy from corrosion for a long time. It was found that an increase in the thickness of inhibitor film occurs in parallel with a sharp decrease in its resistance. In view of this, it was assumed that excessive deposition of cerium results in the formation of more defective deposits. The highest $C_{\text {in }}$ provided the best corrosion protection only at the beginning of exposure, while the lowest $C_{\text {in }}$ was more useful after a few hours. Besides, the SVET method revealed corrosion acceleration induced by cerium on an $\mathrm{Al} / \mathrm{Cu}$ model at the first instants of immersion. Using the ToF-SIMS method, the distribution of particles over the depth of the alloy was estimated.

The ability of BTA or its substituted derivatives to increase the corrosion resistance of aluminum alloys containing a significant amount of copper and zinc was found to be useful in the preparation of chromate-free conversion coatings (CC). This property was successfully used by S.V. Oleynik et al. who developed chromate-free CC on a number of aluminum alloys. So, already in [31], it was shown that the IFKhANAL-1 composition based on a molybdate-borate alkaline solution forms a more stable CC on D16 alloy, which belongs to the $\mathrm{Al}-\mathrm{Mg}-\mathrm{Cu}$ alloy system, than a soda-molybdate solution. However, it is inferior in protective properties of the $\mathrm{CC}$ formed in a soda-chromate solution. The reason for this lies in the presence of a significant amount of copper oxides and metallic copper in the protective film formed by IFKhANAL-1, as the XPS method proved. To mitigate this disadvantage of a chromate-free $\mathrm{CC}$, the authors introduced BTA or 8-HQ, which form stable complexes with copper cations, in IFKhANAL-1. In both cases, this gave a beneficial result even in corrosion tests in a solution containing $3 \% \mathrm{NaCl}+0.1 \% \mathrm{H}_{2} \mathrm{O}_{2}$, although 8-HQ was somewhat more effective.

Another high-strength alloy B95, a representative of the Al-Mg-Cu-Zn system (A7075 alloy according to ASTM classification), despite its high strength, has low corrosion resistance, and the search for a replacement of conversion chromate-containing compounds remains relevant. Its oxidation in an IFKhANAL-1 solution gives a CC with a thickness of $3.8 \mu \mathrm{m}$ that is less stable than the coating formed in a chromate-soda solution [32]. However, in contrast to filling the $\mathrm{CC}$ with a solution containing $10 \mathrm{~g} / \mathrm{L} \mathrm{BTA}$ on the D16 alloy, in this case the pitting resistance of the $\mathrm{CC}$ on the B95 alloy could not be increased. This is explained by the presence of a larger amount of zinc than copper compounds in the $\mathrm{CC}$. The best result that is close to chromate coating was obtained upon filling of the $\mathrm{CC}$ formed in 
IFKhANAL-1 with an alkaline solution of dibenzothiazole disulfide known under the Altax trademark. The authors explained this by the fact that Altax has better complexing properties toward zinc than BTA.

Later, the IFKhANAL-3 alkaline chromate-free conversion composition was developed, which is capable of forming a protective $\mathrm{CC}$ on a wider set of aluminum alloys. As a rule, it is not inferior to chromate coatings [33]. For alloys with a low copper content (AB00, AD 31, AMg, 1424, etc.), filling such CCs with an aqueous solution of the wellknown organic inhibitor IFKhAN-25 is especially effective [3], but in the case of CC on copper-aluminum alloys, for example, D16 or 1370, this operation should be performed with BTA added to it $[33,34]$.

Treatment of V95T2 alloy in an IFKhANAL-3 solution formed a CC $3.4 \mu \mathrm{m}$ thick in $50 \mathrm{~min}$, which was not inferior in protective properties to a standard chromate coating. If BTA or its substituted derivative, TTA, is added to the conversion solution, then the thickness of the CC reaches 4.0 or $5.0 \mu \mathrm{m}$, respectively [35]. Such CCs after filling with the IFKhAN-25 solution noticeably surpass chromate CC in the protection efficiency in G-4 humidity chamber (GOST 9.913-90): the time until the first pits $(\tau)$ appear reaches 22 days, while chromate passivation provides only 15 days.

Alloy 1441 is of interest. It is considered as a possible replacement for alloy D-16 since it is comparable with the latter in strength, its specific density is lower by $7 \%$, and its elastic modulus is higher by $12 \%$ [36]. This $\mathrm{Al}-\mathrm{Cu}-\mathrm{Mg}-\mathrm{Li}$ alloy is especially promising for the aerospace industry, therefore, creating a protective chromate-free $\mathrm{CC}$ on it is very important. In view of this, the authors studied the possibility of forming a coating on this alloy in an IFKhANAL-3 conversion solution with addition of BTA or its substituted derivatives (TTA, 5-chloro-BTA). It was found that such CCs well adhere to the substrate and inhibit not only anodic but also cathodic reactions in an aqueous buffer solution $(\mathrm{pH} 7.36)$ containing $0.01 \mathrm{M}$ $\mathrm{NaCl}$. Corrosion tests in a humidity chamber showed that the best resistance is demonstrated by CCs formed in IFKhANAL-3 solution containing BTA and filled with an IFKhAN-25+ BTA aqueous solution. In this case, the value of $\tau$ reaches 35 days.

The same authors [37] studied the chemical oxidation of Li-containing aluminum alloy 1424 (4.6-5.2\% Mg, $1.5-1.8 \% \mathrm{Li}, 0.4-0.8 \% \mathrm{Zn}, 0.05 \% \mathrm{Mn}, 0.04-0.05 \% \mathrm{Sc}$ ) in IFKhANAL-3 chromate-free formulation to obtain a protective CC. They showed that the addition of complexing reagents Trilon B and BTA to this formulation improves the properties of the $\mathrm{CC}$ and that their subsequent filling with an aqueous solution of IFKhAN-25 inhibitor increases the protective properties. They latter were estimated by the length of the passive potential region on the anodic polarization curves obtained in a chloride-containing borate buffer. It qualitatively correlates with the oxidation time of the alloy and, accordingly, with the thickness of the $\mathrm{CC}$ that reaches almost 7 microns in 50 minutes. Decreasing the oxidation temperature from 80 to $60^{\circ} \mathrm{C}$ slightly weakens the protective ability of the $\mathrm{CC}$, but to a lesser extent than decreasing the $\mathrm{pH}$ of the conversion solution. In contrast, when such a solution is used repeatedly, the $\mathrm{CC}$ acquires enhanced protective properties due to an increase in the coating thickness resulting from the 
accumulation of alloy dissolution products in the solution. Filling CCs in solutions containing various amounts of an CI showed a significant effect on the coating hydration.

The presence of BTA in $\mathrm{n}$ corrosive environment has a positive effect on the stability of various alloys not only against corrosion, but also against corrosion fatigue, for example, of an $\alpha$-Al-bronze containing in wt.\%: $7.0 \mathrm{Al} ; 0.04 \mathrm{Fe}$; $0.01 \mathrm{Ni} ; 0.04 \mathrm{Si} ; 0.006 \mathrm{Mg}$, the rest $\mathrm{Cu}$. For example, the authors of [38] studied the effect of BTA on the corrosion-fatigue behavior of the $\alpha$-Al-bronze in $1 \mathrm{M} \mathrm{LiBr}$ solution by the reverse bending method. The $\alpha$-bronze that underwent fatigue tests in $1 \mathrm{M} \mathrm{LiBr}$ had a smaller fatigue resistance than the $\alpha$-bronze tested in the air. They showed that the presence of $0.02 \mathrm{M}$ BTA in the solution improves the fatigue endurance to a value close to that of $\alpha$-Al bronze in the air. Optical and scanning electron microscopy of the $\alpha$-Al bronze that underwent fatigue tests in the air showed that the fractures were transgranular, though the initiation of the fatigue crack and its propagation were transcrystalline.

\section{Paintwork and other protective coatings}

As already discussed in our reviews on the protection of other metals ( $\mathrm{Cu}$ and $\mathrm{Zn}$ [11], Fe and steels [16]) with BTA and its substituted derivatives, an important method of using CIs is to introduce them into a paint and varnish coatings (PVC) system. Since direct addition of a CI into a coating can cause its undesirable chemical interaction with the binder and other process additives, extensive studies are currently underway to find nano- or microcontainers from a neutral material that are filled with the appropriate CI and only then added to the PVC. In such cases, several strict requirements are imposed on the CIs: environmental safety, chemical and thermal stability, versatility and high efficiency of protective action toward several metals and alloys, as well as the ability to diffuse from the containers to reach the metal surface and relatively quickly form a protective layer on it. Coatings containing encapsulated CIs are often referred to as self-healing or "smart".

Development of protective coatings with the property of self-healing of defects that may appear during operation of the product, i.e., the creation of active corrosion protection systems for metals, is a very important task for many industrial applications that previously used chromate pigments and CIs. When looking for a replacement for chromates, it must be remembered that its substitute must not only be an effective CI of the metal in the aqueous solution but must also have optimal solubility in it. If the CI has too low solubility, then it will be released from the nanocontainer too slowly and will reach the defect site in insufficient amount. This will not allow it to heal the defect quickly. A too high solubility of a CI will allow it to protect the metal, but only for a relatively short time since it will quickly be washed out of the coating.

Another drawback of such a CI is osmotic pressure, which leads to the formation of bubbles and delamination of protective coatings. It can accelerate the penetration of water through the coating, making it a semipermeable membrane. This will destroy the barrier layer, which limits the possibility of using inorganic CIs such as borates, molybdates and even chromates. 
In [38], a method was suggested for modifying particles of water-soluble organic CIs with BTA, TTA, and 1,2,4-triazole chosen as such CIs. Using plasma polymerization, the authors obtained thin polymer films on the surface of these powdered organic CIs, thus turning their surfaces from hydrophilic to hydrophobic. FTIR, time-of-flight secondary ion mass spectrometry (ToF-SIMS), scanning electron microscopy combined with energydispersive X-ray spectroscopy (SEM/EDX), transmission electron microscopy (TEM), and contact wetting angle measurements confirmed the successful application of a thin polymer film on CI particles. By immersing the samples in a solution and electrochemical methods of analysis, it was shown that encapsulated water-soluble CIs can be slowly released into the environment and protect the AA2024-T3 plates from corrosion with efficiency no worse than chromate pigments. As a result, the authors concluded that the suggested method is very promising and can replace chromate pigments, for example, in water-borne epoxy paints.

An example of the use of BTA as an encapsulated CI is provided by the study of Schukin et al. [40]. They used the technology of layer-by-layer (LbL) deposition of oppositely charged particles (in particular polyelectrolytes) from their solutions on a substrate surface [41] to prepare nanocontainers with controlled BTA storage/release properties. Although ion-exchange resins were previously studied as "smart" reservoirs for CI storage (anion exchangers adsorbed corrosive chlorides and released CI anions into a corrosive medium), polyelectrolyte assemblies were not previously used in PVC, although storing CI in multilayer polyelectrolytes provides certain advantages. The latter include the absence of a negative influence of the CI on the coating stability, the lower effect of coating polymerization on the CI, and the possibility of ensuring a "smart" exit of a CI from the assembly, since its permeability is sufficient to be controlled primarily by changes in $\mathrm{pH}$, humidity, or light. The sensitivity to $\mathrm{pH}$ is especially important since corrosion causes local $\mathrm{pH}$ changes in the case of cathodic (alkalization) and anodic (acidification) reactions. Consequently, electrochemical reactions causing metal corrosion can initiate the release of a CI from polyelectrolyte reservoirs (PER), i.e., activate its protective effect.

For example, PERs themselves in sol-gel anticorrosion coatings are required to be compatible with the sol-gel matrix material (to prevent matrix distortion) and to have a nanometer size to be evenly distributed in the matrix. To form self-healing protective coatings on AA20 alloy, the authors chose $\mathrm{SiO}_{2}$ nanoparticles $(70 \mathrm{~nm})$ LbL-coated with polyelectrolyte molecules, which served as the PER for BTA incorporated into a hybrid solgel protective coating. BTA release is triggered by $\mathrm{pH}$ changes upon corrosion of the aluminum alloy.

PERs increased the duration of corrosion protection of the coated aluminum substrate due to reliable storage of the CI and its long-term release "on-demand" on damaged surface areas. Thus, active protection of the aluminum alloy from corrosion was ensured, along with the possibility of self-healing of coating defects. The authors concluded that the use of BTAloaded PERs in anti-corrosion coatings on aluminum alloys opens up the possibility of creating easy-to-make and economical alloy protection systems with active feedback from corrosion processes that can provide effective self-healing of coating defects. 
Another work [42] dealt with a self-healing protection system for AA2024 alloy consisting of hybrid sol-gel films based not only on $\mathrm{SiO}_{2}$ but also on $\mathrm{ZrO}_{2}$. It was doped with PERs that released a trapped CI, i.e., BTA, in response to $\mathrm{pH}$ changes caused by the corrosion process. It was confirmed that such a hybrid film with nanocontainers provided better corrosion protection of the alloy than the same film without BTA nano-containers. It was shown by the SVET method that the efficiency of defect self-healing was achieved due to the controlled release of BTA caused by corrosion processes in the coating defects.

Later, in $[44,45]$, the adverse role of BTA was proved when it was introduced into hybrid thin films obtained by the sol-gel method on the AA 2024-T3 aluminum alloy. The CIs were introduced into the coating composition in order to study their active protective effect. It was studied by EIS and SVET electrochemical methods, as well as by accelerated corrosion tests in a salt fog chamber. It was shown that in most cases, addition of a CI to sol-gel coatings leads to an improvement in active protection against corrosion, but it can also negatively affect the barrier properties of the films. The authors concluded that encapsulation of CIs, including BTA, is beneficial for combining a good barrier function of the coating with the action of a CI that inhibits the corrosion of the alloy.

In subsequent years, owing to encapsulation that eliminated its main drawback, BTA continued to be intensely studied as a CI for various anti-corrosion coatings. Shchukin et al. [46] studied the efficiency of protection of AA2024 aluminum alloy by an active coating consisting of a hybrid $\mathrm{SiO}_{2}-\mathrm{ZrO}_{2}$ film doped with a mesoporous $\mathrm{SiO}_{2}$ nanocontainer loaded with BTA, but without an additional polyelectrolyte shell, in contrast to the study discussed above [42]. If these porous particles embedded in the coating were near a defect, they released BTA upon attack by chlorides, which healed the defect. They found that these nanoparticles can have a high BTA content, thus providing superior alloy protection performance while being easy to manufacture.

The mesoporosity, monodispersity, and spherical morphology of the studied silica nanoparticles contribute to the efficiency of CI loading into them, which is much higher than those previously achieved for similar systems. Besides, the inclusion of these loaded nanoparticles into a $\mathrm{SiO}_{x} / \mathrm{ZrO}_{x}$ sol-gel matrix ensured a uniform distribution of nanocontainers, as well as uniformity over the coating thickness, blocking of micropores and cracks, and improving the barrier properties of the coating. SEM and SVET measurements confirmed that when corrosion occurs, due to $\mathrm{pH}$-stimulated emission of $\mathrm{CI}$ its protective properties and self-healing of defects by it are manifested clearly. Studies show advantages of the nanocontainers synthesized from mesoporous silicon dioxide and an improvement in the protective coating activity.

Simultaneously with the development of methods for filling BTA nanocontainers based on $\mathrm{SiO}_{2}$, an active search for other materials suitable for the same purpose was carried out. Halloysite $\mathrm{Al}_{2} \mathrm{Si}_{2} \mathrm{O}_{5}(\mathrm{OH})_{4} \cdot n \mathrm{H}_{2} \mathrm{O}$, which is a two-layer (1:1) natural aluminosilicate clay, is among the very promising natural and non-toxic materials. It has a hollow tubular structure and is chemically similar to kaolin. 
According to $[47,48]$, reagents loaded into halloysite nanotubes, in particular BTA, are protected from leaching or other possible environmental hazards, but can be released by a certain signal, for example, $\mathrm{pH}$ changes, and delivered to a coating defect that formed. Addition of a small amount of BTA-loaded halloysite to coating matrices does not decrease the initial barrier properties of a sol-gel coating. Besides, its anti-corrosion efficiency is enhanced and can provide self-healing of coating defects.

In [49], BTA was loaded into halloysite tubes with a diameter of $50 \mathrm{~nm}$ and the latter were introduced (2-10 wt.\%) into a coating, which increased its strength by a factor of $2-4$. BTA was released from halloysite nanotubes in $\sim 50$ hours, and the kinetics of this process was described by a power function. To prove the efficiency of corrosion inhibition of AA 2024 alloy and copper by these BTA-containing nanocontainers, the local corrosion current density on scratches was measured. Besides, a significant decrease in the corrosion rate of the metal on the scratched metal sample could be observed visually, since severe corrosion took place at the scratched sites in the absence of nanocontainers with BTA in the coating. The possibility of more efficient BTA loading into halloysite nanotubes and control of the CI release rate from them to obtain the best protective properties of a coating was also noted. This is very important where a painted surface is exposed to a flow of water that causes premature $\mathrm{CI}$ release and its removal from the metal surface.

The anion-exchange mineral hydrotalcite $\mathrm{Mg}_{6} \mathrm{Al}_{2}(\mathrm{OH})_{16} \mathrm{CO}_{3} \cdot 4 \mathrm{H}_{2} \mathrm{O}$ can be used as a pigment to combat filiform corrosion of metals (FFC) [50]. FFC is a kind of atmospheric corrosion of metals that is observed on aluminum alloys coated with organic coatings. The presence of $\mathrm{O}_{2}$, relative atmospheric humidity of at least $60 \%$ and corrosive anions, most often chlorides, are required for it to appear. "Filamentary" deposits of corrosion products under the coating contain an "active head" filled with a concentrated aqueous electrolyte and a "tail" of dry corrosion products. They are developed from through defects in the organic coating. In this case, the surface diffusion of $\mathrm{O}_{2}$ arising in the tail part of the filament forces the anodic dissolution of the metal to occur at the leading edge, and cathodic reduction of oxygen occurs at the trailing edge of the active head. In the case of an aluminum alloy, partially hydrolyzed $\left[\mathrm{Al}\left(\mathrm{H}_{2} \mathrm{O}\right)_{6}\right]^{3+}$ cations continuously migrate to the trailing edge cathode, while anions $\left(\mathrm{OH}^{-}, \mathrm{Cl}^{-}\right)$migrate to the leading edge anode. The interaction of aluminum cations and $\mathrm{OH}^{-}$creates insoluble aluminum oxide/hydroxide precipitates following the advancing filament head. Corrosive anions tend to persist in the electrolyte from the filament head, and constant cationic hydrolysis maintains a low $\mathrm{pH}$ (close to 1) at the leading edge of the head. The alloy continues to dissolve, and the filaments can grow for long periods (even years) to reach several centimeters in length. First, it was shown that chromate anions previously absorbed by hydrotalcite, when introduced into a polyvinyl butyral (PVB) coating on AA 2024-T3 alloy, are displaced by chlorides due to anion exchange and perfectly prevent the origination of FFC. However, later, due to the toxicity of chromates, the same authors attempted to find a replacement for them with less environmentally hazardous organic anionic CIs that must first be absorbed by hydrotalcite [51]. 
In this context, they studied sodium benzotriazolate (NaBTA), potassium ethyl xanthate, and sodium oxalate as CIs. For this purpose, PVB solutions in ethanol containing inhibited hydrotalcite dispersions were applied on AA2024-T3 rods and after drying in air, films with a thickness of $30 \mathrm{~mm}$ with a pigment volume fraction of 0.2 were obtained. FFC was induced by making a $10 \mathrm{~mm}$ long scratch in the center of each coated sample and applying $1 \mathrm{ml}$ of an aqueous solution of $0.5 \mathrm{M} \mathrm{HCl}$. After that, all samples were kept for 1 week at a constant temperature of $20^{\circ} \mathrm{C}$ and a relative humidity of $93 \%$. It was found that the efficiency of CIs absorbed by hydrotalcite increased in the following series: potassium ethyl xanthate $<<$ sodium oxalate $<\mathrm{NaBTA}$. Although the best of them, i.e., NaBTA, was inferior in efficiency to chromate, it was concluded that pigments bearing organic $\mathrm{CI}$ anions deserve further study for the prevention of corrosion-induced delamination of organic coatings.

It should be noted here that layered double hydroxides (LDH) are among the most promising types of ion exchangers. They consist of packets of positively charged mixed metal hydroxides stabilized by anions and solvent molecules sandwiched between the positive layers. The mechanism for the release of particles, including CIs, from LDH is based on anion exchange. For corrosion protection, LDHs can be used in dual role: releasing anionic CIs and trapping corrosive anionic substances such as chlorides. Besides, the release of $\mathrm{CI}$ can also be indirectly caused by $\mathrm{pH}$ changes: at very high $\mathrm{pH}$, CIs can be replaced by $\mathrm{OH}^{-}$anions, and at very low $\mathrm{pH}, \mathrm{LDH}$ dissolve to release trapped CIs. In a review article by Zheludkevich et al. [52] that considered "smart" coatings for the active anticorrosive protection of metals, much attention was paid to LDH. They are prepared by a variety of methods, including ion exchange and coprecipitation methods, as well as rehydration calcination, to form a universal structure for separation of various inorganic or organic anions. Overall, their studies have shown that the mechanism of CI release by anion exchange is kinetically fast and driven by chemical equilibrium. It was noted that oxide films play an important role in the protection of aluminum alloys by such coatings, which have the maximum resistance when LDHs are present in the primer. Besides, the barrier properties of the coating itself are superior to an LDH doped primer.

It is noted that microcapsules loaded with 2-MBT provided better barrier properties of the coating than microcapsules filled with chromate. Introduction of such capsules into a primer made it more resistant to FFC than the presence of chromates in the primer. This shows the importance of encapsulating organic CIs before their introduction into the primer for the stability of both the barrier properties of the coating and the natural oxide layer on the aluminum alloy being protected. It is significant that, as SVET measurements showed, the self-healing of defects occurs more easily in the presence of capsules with MBT than in the case of a primer containing chromate. This advantage of MBT-filled microcapsules is due to the rapid release of the CI immediately after the rupture of the polymer coating in the scratched area. However, it should be remembered that an excess of MBT can cause the formation of bubbles on the surface to be protected. 
At the same time, the authors of the review believe that nanocontainers coated with polyelectrolyte shells by the LbL method are of great interest due to the $\mathrm{pH}$-triggered mechanism of CI release, but its "increase is limited due to the LbL methodology". In contrast, the LDH method offers more opportunities and can be cost-effective. Here they also mean the use of inorganic systems that can have mechanical and thermal stability, which allows them to be used in various coating layers (pretreatment, primer, topcoat). This is less likely for polymer capsules since their use is limited to coating layers that are not subject to high mechanical stress or significant thermal stress. The assumption was also made that combining various CIs with various "smart" nano- and microcontainers to obtain multifunctional coatings with their respective immobilization/release mechanisms can be a way for optimizing the composition and properties of protective coatings.

Indeed, a couple of years later in [53], a new concept was suggested for active corrosion protection of galvanically coupled multicomponent structures. It is based on a combination of two types of nanocontainers with two different CIs in one coating system, where the CIs have a synergistic protective effect. Nanocontainers provide a triggered release of both CIs, i.e., their exit from the container begins as a response to changes in external conditions, for example, the appearance of corrosion of a coated aluminum alloy or a change in the $\mathrm{pH}$ of the environment. Layered double hydroxide and bentonite were used as functional nanocarriers for BTA and $\mathrm{Ce}^{3+}$, respectively, which, as discussed above [28-30], are capable of protecting metals synergistically. The case where an aluminum alloy is galvanically bonded to a carbon fibre-reinforced plastic (Al/CFRP) is considered. The SVET method was used to monitor galvanic corrosion and the kinetics of self-healing processes in closed defects. For the first time, effective inhibition of electrochemical activity in defects of a coated galvanically coupled aluminum alloy with Al/CFRP was demonstrated. The synergistic combination of BTA and $\mathrm{Ce}\left(\mathrm{NO}_{3}\right)_{3}$ demonstrated an excellent corrosion protection effect for uncoated Al/CFRP galvanic couple in a chloride environment.

It has long been known that 2-MBT and BTA are not only promising $\mathrm{CI}$ for aluminum alloys but are weak acids (with $\mathrm{p} K_{\mathrm{a}} 7.20$ and 8.38, respective). In view of this, both CIs can be included in protective coatings in the form of anions. For example, they can be embedded into intermediate layers of SDH. The capacity and characteristics of such LDH nanocontainers substantially depend on the location of the anions in their intermediate layers. M. Serdechnova et al. [54] studied the incorporation of 2-MBT- and BTA- into $\mathrm{Mg}-\mathrm{Al}-$ $\mathrm{NO}_{3}$ and $\mathrm{Zn}-\mathrm{Al}-\mathrm{NO}_{3} \mathrm{LDHs}$ using X-ray diffraction (XRD) methods, including in situ Xray diffraction. It was found that the anion exchange of nitrate anions with 2-MBT or BTA occurs much faster than it was believed previously. In $20 \mathrm{~min}$, an exchange reaction at room temperature and $\mathrm{pH} \mathrm{11,} \mathrm{which} \mathrm{is} \mathrm{necessary} \mathrm{to} \mathrm{maintain} \mathrm{the} \mathrm{anionic} \mathrm{form} \mathrm{of} \mathrm{these} \mathrm{CIs,}$ allowed the following well-formed LDHs to be obtained: $\mathrm{Mg}-\mathrm{Al}-\mathrm{MBT}, \mathrm{Zn}-\mathrm{Al}-\mathrm{MBT}$, $\mathrm{Mg}-\mathrm{Al}$-BTA. However, under the same conditions, $\mathrm{Zn}-\mathrm{Al}-\mathrm{BTA} \mathrm{LDH}$ was not obtained due to the irreversible reaction between BTA and Zn oxide/hydroxide layers. Substitution of nitrates by organic anions occurs with participation of hydroxide anions. Although there is no intermediate $\mathrm{LDH}$ phase intercalated by the combination of $\mathrm{NO}_{3}^{-}$and $\mathrm{OH}^{-}$, the 
formation of the LDH-MBT and LDH-BTA phases also leads to the appearance of the $\mathrm{LDH}$ phase intercalated with $\mathrm{OH}^{-}$at the final stage of anion exchange. 2-MBT and BTA form a double layer in the intermediate layer of $\mathrm{LDH}$, in which they have an oblique orientation relative to the layer plane (in the form of a herringbone). This arrangement corresponds to the electroneutrality of the LDH layer and is in good agreement with the observed values of the interlayer distance. It does not match the symmetry of the double metal hydroxide layers.

Belgian researchers [55] developed a new environmentally friendly method for treating aluminum alloy 2024 to replace CC obtained using Cr(VI) compounds. In this method, a high open porosity of $\mathrm{SiO}_{2}$ was achieved during the preparation of a sol-gel by adding a templating agent (Pluronic P123), which ensured a high content of a CI (namely, BTA) in it. A thin film of mesoporous $\mathrm{SiO}_{2}$ synthesized by the self-assembly process upon evaporation was doped with BTA to obtain active corrosion protection. For this purpose, samples with a mesoporous film were immersed for one day in an ethanol solution of BTA with $C_{\text {in }}=0.1$; $1.0 ; 5.0$ or $20 \mathrm{~g} / \mathrm{L}$. The balance between the pore diameter and BTA size was clearly determined by observing the penetration of its molecules through the mesopores. At this stage, the release of BTA had a positive effect on the protection of the alloy against corrosion.

However, it was noted that the loaded mesoporous film could not completely suppress the corrosion of the AA 2024 substrate. The large volume of open pores inside the layer could not prevent the diffusion of corrosive particles to the substrate surface, the area of which is too large compared to the amount of BTA exiting the mesopores. In view of this, the doped mesoporous film was used in combination with a primer layer that ensured the alloy passivity. An additional barrier layer sealed mesoporosity, confining BTA particles in the active layer and preventing direct contact between the mesoporous film and the corrosive solution, except where defects appeared. Therefore, it was concluded that BTA molecules can be released and play their active role only if the coating is scratched (damaged) or on small metal surface areas. They studied the kinetics of BTA release as a function of $\mathrm{pH}$ change and concluded that the deposition of an alloyed mesoporous film on a 2024 aluminum alloy showed the possibility of its use as layer accumulating an active CI capable of protecting the alloy from corrosion.

Later, the development of a two-layer coating to protect the AA 2024 alloy from corrosion continued [56]. To ensure the storage and release of BTA molecules (active protection), a thin mesoporous $\mathrm{SiO}_{2}$ film was applied to the alloy surface, followed by a barrier acrylic layer atop of it (passive protection). Scanning electrochemical microscopy (SEM), SVET and recording of anodic polarization curves inside the scratch using an electrochemical microelement were used to estimate the anticorrosive properties of the coating. All the results obtained confirm that BTA can be released from the mesoporous film and slow down the corrosion of the "bare" alloy in the scratch. This shows not only the ability of mesoporous films to serve as a reservoir for BTA particles that are effective CIs of the alloy in case of controlled release, but also the value of electrochemical measurements 
on microelements for the release of active protection in the event of defects in a coating containing a CI.

Although the positive effect of BTA was confirmed when a coating was scratched, the corrosion protection in this defect was not long-lasting. This can be explained by the limited amount of $\mathrm{CI}$ released from mesoporous $\mathrm{SiO}_{2}$ and the absence of its excess in the corrosive environment. To increase the long-term protection of the alloy, it is necessary to combine the pre-treatment of mesoporous $\mathrm{SiO}_{2}$ with a BTA solution with a more perfect top layer of the coating, for example, a polymer with self-healing properties. In this case, the action of BTA is capable of delaying the development of corrosion inside a defect for the period necessary for the polymer to restore its initial barrier properties.

The authors of [57] investigated the effect of $\mathrm{Y}_{2} \mathrm{O}_{3}$ and $\mathrm{Al}_{2} \mathrm{O}_{3}$ as a stabilizer for a nanostructured $\mathrm{ZrO}_{2}-\mathrm{BTA}$ coating. They showed that the nanostructured $\mathrm{ZrO}_{2}-\mathrm{BTA}$ coating is uniform and has no cracks. Addition of $\mathrm{Al}_{2} \mathrm{O}_{3}$ and $\mathrm{Y}_{2} \mathrm{O}_{3}$ resulted in a decrease in the roughness of the coatings. The presence of alumina as a stabilizer for the $\mathrm{ZrO}_{2}$ coating increases the corrosion resistance of the coating at different immersion times. It was found that the presence of $\mathrm{Y}_{2} \mathrm{O}_{3}$ oxide initially improves the corrosion resistance of $\mathrm{ZrO}_{2}-\mathrm{BTA}$, but penetration of water and diffusion of ions such as $\mathrm{Cl}^{-}$over time reduced the healing ability of the defects and corrosion of the alloy occurs.

The results obtained confirmed the formation of homogeneous nanostructured coatings based on $\mathrm{ZrO}_{2}$ - BTA and the absence of cracks on them. The average roughness values of the nanostructured coatings $\mathrm{ZrO}_{2}-\mathrm{BTA}, \mathrm{ZrO}_{2}-\mathrm{Al}_{2} \mathrm{O}_{3}-\mathrm{BTA}$, and $\mathrm{ZrO}_{2}-\mathrm{Y}_{2} \mathrm{O}_{3}-\mathrm{BTA}$ were 30,8 , and $6 \mathrm{~nm}$, respectively. An important role in enhancing the corrosion resistance of the alloy at different immersion times is played not only by the CI, i.e., BTA, but also by stabilization of the zirconium oxide coating due to incorporation of alumina. Its addition led to the dominance of repair of coating defects in competition with the corrosion of the $\mathrm{ZrO}_{2}-$ BTA coating.

In development of self-healing anticorrosive coatings for aluminum alloy 2024, attempts were made to use titanium oxides as CI reservoirs [58]. BTA was used as the CI since it can suppress the corrosion of copper-rich intermetallic compounds on the surface of AA 2024-T3 alloy. To do so, a $0.05 \mathrm{~g} / \mathrm{L}$ solution of BTA in ethanol was used for preliminary loading of nanoporous $\mathrm{TiO}_{\mathrm{x}}$ reservoirs that were formed a porous layer on the alloy surface obtained by template synthesis. This provides active protection of the alloy against corrosion and the self-healing capability of the coating system. The reservoir is composed of titanium dioxide nanoparticles forming a cellular network that follows the structure of the etched alloy surface. The layer of nanoreservoirs was covered with a thin sol-gel hybrid film to provide an additional barrier effect.

The morphology of the $\mathrm{TiO}_{2}$ based film was characterized by FE-SEM and AFM. The protective properties of the films were studied by EIS and SVET methods. The methods developed for the treatment of the alloy surface showed better protection against corrosion than the films obtained from an undoped sol-gel or by direct BTA incorporation into the sol-gel matrix. The treatment using a nanostructured layer of $\mathrm{TiO}_{2}$ reservoirs coated with a 
hybrid film featured a pronounced ability of the coating to self-heal defects and offered longterm active protection of the alloy against corrosion. The nanostructured porous $\mathrm{TiO}_{2}$ layer provides a vast surface area for BTA adsorption. Owing to the developed surface of the selfcollected layer, good adhesion between the oxide and the sol-gel film is also observed due to the large interface contact area. Besides, this approach using a nanoscale layer containing BTA made it possible to prevent the negative effect of the CI on the stability of the sol-gel matrix noted previously [59] and facilitated its release in places where coating defects began to develop. This work was one of the first studies to demonstrate the prospects of using nanostructured porous oxide films doped with organic CIs.

In recent years, sol-gel coatings from titanium dioxide containing BTA as the CI on aluminum alloys attracted much interest [60-63]. In [60], nanostructured titaniumaluminum coatings containing 1.2\%, 3.6\% and 4.8\% BTA were deposited on Al 2024 by the sol-gel method, which ensured their self-healing. The surface structure of the alloy strongly affects the strength and adhesion properties of such coatings. A large surface roughness can lead to the appearance of more cracks, while aluminum oxide can reduce the number of defects and cracks in titanium dioxide. The release of BTA from coatings can block active sites and form a barrier layer that increases the corrosion resistance of AA 2024.

Corrosion studies were carried out by the EIS method and by recording polarization curves in $3.5 \% \mathrm{NaCl}$ with the duration of immersion of the electrodes 1, 48 and 96 hours. The best corrosion protection of an alloy coated by a titanium-aluminum composite with a coating thickness of $3 \mu \mathrm{m}$ was observed at a BTA content of $3.6 \%$. This was due to the formation of a homogeneous surface film, which, according to the SEM and AFM images, filling cracks and defects in the coating and prevented the penetration of corrosive electrolyte, and the degree of protection was $Z=76 \%$ (according to the EIS).

To create a corrosion-resistant coating capable of self-healing by the sol-gel method, the authors of $[61,62]$ synthesized it by combining $\mathrm{TiO}_{2}, \mathrm{Al}_{2} \mathrm{O}_{3}$, and BTA on another alloyAA 7075. They found that a change in the amount of BTA in the coating layers significantly changes their properties, which were studied in $3.5 \% \mathrm{NaCl}$ solution using electrochemical measurements, including EIS and polarization tests, by varying the duration of immersion in this solution. EIS studies have shown that the highest resistance for an electrode with a $\mathrm{TiO}_{2}+4.2 \%$ BTA coating was observed even after 120 hours of immersion. BTA acted in the coating as a CI and a "healing" agent by two mechanisms [61]. First, its release from the coating led to the formation of corrosion products that blocked surface defects. Second, the release of BTA within 48 hours after immersion and its adsorption created an insulating layer on the coating surface in contact with the solution.

The microstructural and morphological properties of the coatings were characterized using X-ray phase analysis, Raman spectroscopy, field emission scanning electron microscope (FESEM) and AFM, respectively [62]. According to AFM results, the thickness of all coatings was less than $200 \mathrm{~nm}$. Analysis of the coating surface using Raman spectroscopy revealed chemical bond groups such as $\mathrm{Ti}-\mathrm{O}-\mathrm{Ti}, \mathrm{Ti}-\mathrm{O}$ and $\mathrm{O}-\mathrm{C}-\mathrm{C}$. $\mathrm{X}-\mathrm{Ray}$ analysis showed that the structure of the coatings formed was completely amorphous, and 
FESEM images allowed the conclusion to be made that the coatings were uniform on all the samples. Nanostructured coatings with uniform grain distribution were obtained by optimizing the amount of BTA. The self-healing behavior of hybrid ceramic coating were studied using electrochemical measurements, including EIS and polarization tests in 3.5 wt.\% $\mathrm{NaCl}$ solution in different periods. The results of corrosion studies showed that after 96 hours of testing in the chloride solution, BTA can prevent the development of corrosion of the alloy due to the self-repair ability of the coatings, which improves the corrosion resistance of the alloy compared to its uncoated samples by a factor of about 130 .

Recently, the authors of [63] studied the corrosion behavior of AA 2024-T3 alloy protected by self-healing nanostructured and functionally-gradient coatings (FGC) of titanium dioxide. The FGC were applied using the sol-gel technology by dipping of samples, and BTA, which was contained in all layers in the same amount, played the role of the CI. The studies were carried out in an aqueous 3.5\% $\mathrm{NaCl}$ solution for 96 hours, and the corrosion resistance of FGC with a thickness of $d=2.6 \mu \mathrm{m}$ was studied by taking polarization curves and EIS in comparison with an amorphous $\mathrm{TiO}_{2}-\mathrm{Al}_{2} \mathrm{O}_{3}-\mathrm{BTA}$ coating $(d=2.3 \mu \mathrm{m})$. The protection of the alloy by these coatings was due to the presence of BTA in them, which helped to form a thin passive film mainly consisting of $\mathrm{Al}_{2} \mathrm{O}_{3}$ on the alloy. FGC provides better corrosion resistance than amorphous $\mathrm{TiO}_{2}-\mathrm{Al}_{2} \mathrm{O}_{3}-\mathrm{BTA}$ coating, which the authors explain by two reasons. One of them was the possibility of introducing different BTA concentrations into a FGC (they were varied from 1.2 to $4.8 \%$ ), which made it possible to control the release of BTA from the FGC. Another reason is associated with the greater surface roughness of the nanostructured $\mathrm{TiO}_{2}-\mathrm{Al}_{2} \mathrm{O}_{3}-\mathrm{BTA}$ coating, which increases the number of corrosion centers. It should be added that the lower defectiveness of passivating films for FGC, as was already noted many times in the discussion of the protective action of BTA, is largely due to the ability of this CI to block the negative effect of copper-containing intermetalides on the surface of an aluminum alloy. It is not surprising that the authors recommend the use of FGC to protect aluminum alloy AA 2024-T3 in practice.

\section{Acid environments}

Aluminum and its alloys are highly susceptible to oxidation; therefore, their surface is always covered with a thin oxide layer, which is formed already upon contact with atmospheric air. However, aluminum oxide is readily soluble in acid and alkaline media, i.e., at $\mathrm{pH} \leq 5$ or $\mathrm{pH} \geq 9$. Industrial aluminum alloys can corrode during acid etching, acid cleaning and chemical or electrochemical etching. $\mathrm{HCl}$ and $\mathrm{H}_{2} \mathrm{SO}_{4}$ solutions are considered to be the most common corrosive media. The use of CIs is among the most efficient ways to reduce the corrosion rate of aluminum alloys.

Organic CIs, whose protective properties toward aluminum alloys in $\mathrm{HCl}$ solutions are already known, belong to the classes of aliphatic amines [64], Schiff bases [65], amino acids [66], and azoles [67, 68]. A wider set of organic CIs for aluminum and its alloys in acid solutions is presented in a review article [5]. The efficiency of protecting aluminum alloys by organic CIs, like with other metals, depends on their adsorption capability on the metal 
surface. It is determined not only by the chemical structure of their molecules but also by the surface charge, as well as by the chemical composition of the surface layers of the metal or alloy. The composition of the medium, its $\mathrm{pH}$, temperature, concentrations of corrosive components and CI strongly affect the adsorption of a CI.

The capabilities of BTA and its substituted derivatives as CIs for aluminum or its alloys in acid solutions have been studied insufficiently. One of the first works of this kind involved a study of the protective ability of 5-methyl-BTA and $\mathrm{C}_{6} \mathrm{H}_{3} \mathrm{CH}_{3} \mathrm{~N}_{2} \mathrm{NH}$, i.e., tolyltriazole (TTA) [68], in $1.0 \mathrm{M} \mathrm{HCl}$ toward four aluminum alloys containing (in wt.\%): $4 \mathrm{Cu} ; 12 \mathrm{Cu}$; $22 \mathrm{Cu}, 4 \mathrm{Fe}$ and $8 \mathrm{Si} ; 3 \mathrm{Cu}$, respectively. The efficiency of TTA inhibition increased with an increase in the CI concentration but decreased with an increase in temperature (from 150 to $350^{\circ} \mathrm{C}$ ) and $\mathrm{pH}$. The authors also studied the inhibitory effect of TTA in $1.0 \mathrm{M} \mathrm{NaCl}$ solutions (pH 6 and 11) and showed that TTA is a more effective CI at $\mathrm{pH} 0.5$ compared to the other solutions. Alloying components can affect the corrosion rate of alloys in a number of ways. Copper accelerates corrosion in acid, whereas silicon slows it down. The polarization curves of the alloys demonstrated the ability of TTA to slow down cathodic reactions, i.e., it is CI of cathodic type. Like in many cases of corrosion inhibition of aluminum alloys in neutral media with BTA and its substituted derivatives, the protective effect of TTA is due to its adsorption on $\mathrm{Cu}$ particles and formation of a $\mathrm{Cu}(\mathrm{I})-\mathrm{TTA}$ film. The efficiency of the protective action of this $\mathrm{CI}$ increases due to the formation of a $\mathrm{Cu}(\mathrm{I})$ TTA film on the alloy surface. The authors suggested that such a protective film is formed from the interaction of the $\mathrm{CuCl}_{2}$ complex with TTA (in TTA, TTAH, and $\mathrm{TTAH}_{2}^{+}$forms). It was found that the efficiency of corrosion inhibition of alloys by TTA in $\mathrm{HCl}$ solutions ( $\mathrm{pH} 0.5$ ) decreases in the following order: $\mathrm{Al}-8 \% \mathrm{Si}-3 \% \mathrm{Cu}>\mathrm{Al}-22 \% \mathrm{Cu}-4 \% \mathrm{Fe}>\mathrm{Al}-$ $12 \% \mathrm{Cu}>\mathrm{Al}-4 \% \mathrm{Cu}$.

The effect of BTA and its derivatives (5-methyl-BTA, 5-chloro-BTA, and 5-nitroBTA) on the corrosion rate of pure aluminum in a $0.1 \mathrm{M}$ hydrochloric acid solution was studied by potentiostatic polarization [69]. Its corrosion potentials $E_{\text {cor }}$, the values of the Tafel slopes of the anodic and cathodic polarization curves ( $b_{\mathrm{a}}$ and $b_{\mathrm{c}}$, respectively), the corrosion rate $i_{\text {cor }}$, and the efficiency of corrosion inhibition at various concentrations of the CIs studied in hydrochloric acid solution were measured. It was confirmed that BTA and its derivatives predominantly slowed down the cathodic reaction, and the efficiency of their protection of aluminum increased with an increase in the CI concentration. At the same concentration of these compounds $(0.1 \mathrm{mmol} / \mathrm{L})$, the protection efficiency of the CIs increased in the series BTA $<5$-chloro-BTA $<5$-methyl-BTA $<5$-nitro-BTA.

Since the authors concluded that the inhibitory effect of these CIs is due to their adsorption on aluminum surface, they calculated not only the efficiency of aluminum corrosion but also the degree of aluminum surface coverage with adsorbate particles $(\Theta)$ from the results of polarization measurements.

The $\Theta$ values were used to build the adsorption isotherms of BTA, TTA, and 5-chloroBTA and subsequent calculation of the free energy of adsorption $\left(-\Delta G_{\mathrm{a}}^{0}\right)$, which turned out 
to be $17.62,18.39$ and $18.25 \mathrm{~kJ} / \mathrm{mol}$, respectively. Note that this approach is correct under the condition of the blocking mechanism of action of these CIs, and the $\left(-\Delta G_{\mathrm{a}}^{0}\right)$ values obtained from these calculations indicate the physical adsorption of three triazoles. It is characteristic that the adsorption of the best of the inhibitors studied, 5-nitro-BTA, cannot be described by this method. The authors attribute this to the appearance of an additional negative charge in its molecule in comparison with the other CIs studied. At the same time, having measured the values of $i_{\text {cor }}$ of aluminum in $0.1 \mathrm{M} \mathrm{NaCl}$ in the range of $t=20-60^{\circ} \mathrm{C}$ and the kinetic characteristics of corrosion (activation energy $E_{\mathrm{a}}$, enthalpy and entropy), the authors found that the presence of the CIs studied increases $E_{\mathrm{a}}$ of the stage of recombination of hydrogen atoms

$$
\mathrm{H}^{+}+\mathrm{H}_{\mathrm{ads}} \rightarrow \mathrm{H}_{2}
$$

which, according to [70], controls the rate of the cathodic reaction of hydrogen evolution on aluminum in acid solutions.

The authors of [71] studied the corrosion inhibition of the AA 1060 aluminum alloy containing (in wt.\%): $0.35 \mathrm{Fe}, 0.05 \mathrm{Cu}, 0.25 \mathrm{Si}, 0.03 \mathrm{Mn}, 0.03 \mathrm{Mg}, 0.03 \mathrm{Ti}$ and $0.05 \mathrm{Zn}$ by benzimidazole (BIA) and BTA in $0.25 \mathrm{M} \mathrm{HCl}$ solution. They used only electrochemical methods (potentiodynamic polarization, EIS, and electrodynamic noise measurement) and confirmed that the cathodic reaction was predominantly inhibited by both CIs. The EIS method was used to estimate the adsorption of BTA and BIA on the surface of the alloy, which was described by the Langmuir equation. The results allowed the authors to conclude that BTA is more a efficient CI in hydrochloric acid medium since it is better adsorbed on the alloy. In their opinion, this is due to the presence of three nitrogen heteroatoms in BTA (BIA contains two nitrogen atoms) involved in adsorption bonds with the surface.

In recent years, the assessment of the protective properties concerning aluminum began to be carried out using quantum chemical calculations. The most widely used methods for determining the chemical reactivity of organic molecules and clusters are the density functional theory (DFT) methods. In this theory, a solid is considered as a system that includes a large number of electrons interacting in the same way, which are held together by a lattice of atomic nuclei. The calculation method uses the concept of electron density in the ground state, and its distribution is described by the one-particle Schrödinger equation. Unlike the traditional methods for determining the electronic structure, for example, the Hartree-Fock method that describes a system using a many-electron wave function, DFT replaces it with electron density. This simplifies the task since the multielectron wave function depends on variables -3 spatial coordinates for each of the $\mathrm{N}$-electrons, while the density is a function of only three spatial coordinates.

Adsorption of BTA derivatives and phosphonic acids, namely 1-(2-pyrrolcarbonyl)BTA (PBTA), 1-(2-thienylcarbonyl)-BTA (TBTA), 2-phosphonoacetic acid (PAA) and 4phosphonobutyric acid (PBA) on $\mathrm{Al}$ (111) and inhibition of aluminum corrosion by it was studied using quantum chemical calculations and molecular dynamics simulations. 


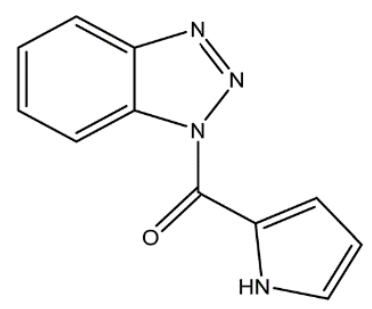

1-(2-pyrrolcarbonyl)-BTA

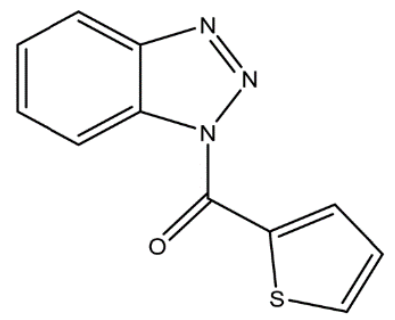

1-(2-thienylcarbonyl)-BTA

The calculations carried out by the authors led them to the conclusion that the binding energies of these compounds with the $\mathrm{Al}$ (111) surface decrease in the order: PBTA $>$ TBTA > PBA > PAA. It is easy to see that a BTA derivative, namely PBTA, may be the best potential CI of aluminum. Unfortunately, the authors did not carry out any corrosion or electrochemical tests on aluminum, and nowhere is it even mentioned that adsorption occurs on an oxidized surface, which is difficult to imagine for such environments as a humid atmosphere or neutral aqueous solution. Most likely, acidic environments are meant. However, even in this case, one can only hope that the efficiency of protection by the studied CIs will coincide with the above order of their binding energy with the $\mathrm{Al}(111)$ surface. Nevertheless, the increased interest in such quantum-chemical calculations and their successful application for simpler systems suggest that in the relatively near future it will be possible to obtain a correlation between the results of measuring the inhibitory effects of benzotriazoles obtained in corrosion tests of aluminum with theoretical quantum-chemical calculations for acid environments.

\section{Conclusion}

BTA and some of its derivatives can behave as CIs of aluminum alloys in neutral and much less often in acid media. An important role in this belongs to their adsorption and ability to block the negative role of copper intermetallides in the corrosion resistance of alloys. This opens up a possibility of using BTA, as well as its substituted derivatives, to obtain protective conversion coatings on aluminum alloys or to enhance the protective properties of various protective coatings. In this case, their good compatibility with other CIs and the possibility of introducing them into coatings in encapsulated form are particularly valuable. Such CIs play an important role in increasing the protective properties and service life of coatings obtained by the sol-gel technology. 
The ability of BTA and its derivatives to slow down the acid corrosion of aluminum alloys has been little studied; nevertheless, it has been found that they mainly slow down the cathodic reaction and that incorporation of a substituent at position 5 of BTA enhances its inhibitory properties in hydrochloric acid solutions.

\section{References}

1. V.S. Sinyavskii, V.D. Val'kov and V.D. Kalinin, Korroziya i zashchita alyuminievykh splavov (Corrosion and Protection of Aluminum Alloys), 1986, Moscow: Metallurgiya (in Russian).

2. Corrosion. Handbook, Ed.: L.L. Schreyer, Abridged translation from English, Ed. V.S. Sinyavsky, 1981, Moscow: Metallurgizdat, 631 (in Russian).

3. Yu.I. Kuznetsov, Organic Inhibitors of Corrosion of Metals, 1996, New York: Plenum Press, 283.

4. A.A. Mikhailov, Yu.M. Panchenko and Yu.I. Kuznetsov, Atmospheric corrosion and metal protection, 2016, Tambov: Pershin Publishing House, 554 (in Russian).

5. K. Xhanari and M. Finšgar, Organic corrosion inhibitors for aluminum and its alloys in acid solutions: A review, RSC Adv., 2016, 6, 62833-62857. doi: 10.1039/C6RA11818F

6. K. Xhanari and M. Finšgar, Organic corrosion inhibitors for aluminum and its alloys in chloride and alkaline solutions, Arabian J. Chem., 2016, 12, no. 8, 4646-4663. doi: 10.1016/j.arabjc.2016.08.009

7. I. Dugdale and J.B. Cotton, An electrochemical investigation on the prevention of staining of copper by benzotriazole, Corros. Sci., 1963. 3, no. 2, 69-74. doi: 10.1016/S0010-938X(63)80001-3

8. Yu.I. Kuznetsov and L.P. Podgornova, Ingibirovaniye korrozii metallov geterotsiklicheskimi khelatoreagentami (Inhibition of metal corrosion by heterocyclic chelating agents), Itogi Nauki, Korroz. Zashch. Korroz., 1989, 15, 132-184 (in Russian).

9. Yu.I. Kuznetsov and L.P. Kazansky, Physicochemical aspects of metal protection by azoles, Russ. Chem. Rev., 2008, 77, no. 3, 219-232. doi: 10.1070/RC2008v077n03ABEH003753

10. M. Finšgar and I. Milošev, Inhibition of copper corrosion by 1,2,3-benzotriazole: A review, Corros. Sci., 2010, 52, 2737-2749. doi: 10.1016/j.corsci.2010.05.002

11. Yu.I. Kuznetsov, Triazoles as a class of multifunctional corrosion inhibitors. A review. Part I. 1,2,3-benzotriazole, its derivatives. Copper, zinc and their alloys, Int. J. Corros. Scale Inhib., 2018, 7, no. 3, 271-307. doi: 10.17675/2305-6894-2018-7-3-1

12. C. Fiaud, Theory and Practice of Vapour Phase Inhibitors, In: Corrosion Inhibitors, 1994, London: The Institute of Materias, 1-12.

13. N.N. Andreev, O.A. Goncharova and S.S. Vesely, Volatile inhibitors of atmospheric corrosion. IV. Evolution of vapour-phase protection in the light of patent literature, Int. J. Corros. Scale Inhib., 2013, 2, no. 3, 162-193. doi: 10.17675/2305-6894-2013-2-3$\underline{162-193}$ 
14. O.A. Goncharova, N.N. Andreev, A.Yu. Luchkin, Yu.I. Kuznetsov, N.P. Andreeva and S.S. Vesely, Protection of copper by treatment with hot vapours of octadecylamine, 1,2,3-benzotriazole, and their mixtures, Mater. Corros., 2019, 70, no 1, 161-168. doi: $\underline{10.1002 / \mathrm{maco} .201810366}$

15. A.A. Khadom, Protection of Steel Corrosion Reaction by Benzotriazoles: A Historical Background, J. Failure Anal. Prev., 2015, 15, no. 6, 794-802. doi:10.1007/s11668015-0043-4

16. Yu.I. Kuznetsov, Triazoles as a class of multifunctional corrosion inhibitors. A review. Part II. 1,2,3-benzotriazole, its derivatives. Iron and steels, Int. J. Corros. Scale Inhib., 2020, 9, no. 3, 780-811. doi: 10.17675/2305-6894-2020-9-3-1

17. K.R. Baldwin, M.C. Gibson, P.L. Lane and C.J.E. Smith, The development of alternatives to chromate inhibitors for the protection of aerospace aluminum alloys, Proceedings of the 7th European Symposium on Corrosion Inhibitors, Ferrara, Italy, 1990, 2, 771-785.

18. C. Monticelli, G. Brunoro and G. Trabanelli, Organic substances as inhibitors of aluminum corrosion in chloride solutions, Proceedings of the 7th European Symposium on Corrosion Inhibitors, Ferrara, Italy, 1990, 2, 1125-1132.

19. L. Bazzi, S. Kertit and M. Hamdani, Some organic compounds as inhibitors for the corrosion of aluminum alloy 6063 in deaerated carbonate solution, Corrosion, 1995, 51, no. 11, 811-817. doi: $\underline{10.5006 / 1.3293558}$

20. M.L. Zheludkevich, K.A. Yasakau, S.K. Poznyak and M.G.S. Ferreira, Triazole and thiazole derivatives as corrosion inhibitors for AA2024 aluminum alloy, Corros. Sci., 2005, 47, 3368-3383. doi: 10.1016/j.corsci.2005.05.040

21. K.S. Bokati and Ch. Dehghanian, Adsorption Behavior of $1 H$-benzotriazole Corrosion Inhibitor on Aluminum alloy 1050, Mild steel and Copper in Artificial Seawater, $J$. Environ. Chem. Eng., 2018, 6, no. 2, 1613-1624. doi: 10.1016/j.jece.2018.02.015

22. V. Palanivel, Y. Huang and W.J. van Ooij, Effects of addition of corrosion inhibitors to silane films on the performance of AA2024-T3 in a $0.5 \mathrm{M} \mathrm{NaCl}$ solution, Prog. Org. Coat., 2005, 53, 153-168. doi: 10.1016/j.porgcoat.2003.07.008

23. W. Qafsaoui, F. Huet and H. Takenouti, Analysis of the inhibitive effect of BTAH on localized corrosion of Al 2024 from electrochemical noise measurements, $J$. Electrochem. Soc., 2009, 156, C67-C74. doi: 10.1149/1.3040281

24. G. Williams, A.J. Coleman and H.N. McMurray, Inhibition of Aluminum Alloy AA2024-T3 pitting corrosion by copper complexing compounds, Electrochim. Acta, 2010, 55, 5947-5958. doi: 10.1016/j.electacta.2010.05.049

25. T.G. Harvey, S.G. Hardin, A.E. Hughes, T.H. Muster, P.A. White, T.A. Markley, P.A. Corrigana, J. Mardel, S.J. Garcia, J.M.C. Mol and A.M. Glenn, The effect of inhibitor structure on the corrosion of AA2024 and AA7075, Corros. Sci., 2011, 53, no. 6, 2184-2190. doi: 10.1016/j.corsci.2011.02.040

26. S. Marcelin and N. Pébère, Synergistic effect between 8-hydroxyquinoline and benzotriazole for the corrosion protection of 2024 aluminum alloy: a local 
electrochemical impedance approach, Corros. Sci., 2015, 101, 66-74. doi: 10.1016/j.corsci.2015.09.002

27. A.C. Balaskas, M. Curioni and G.E. Thompson, Efficiency of 2-mercaptobenzothiazole, 8-hydroxyquinoline and benzotriazole as corrosion inhibitors on AA 2024-T3 assessed by electrochemical methods, Surf. Interface Anal., 2015, 47, 1029-1039. doi: $10.1002 /$ sia. 5810

28. L.B. Coelho, M. Mouanga, M.-E. Druart, I. Recloux, D. Cossement and M.-G. Olivier, A SVET study of the inhibitive effects of benzotriazole and cerium chloride solely and combined on an aluminum/copper galvanic coupling model, Corros. Sci., 2016, 110, 143-156. doi: $10.1016 /$ j.corsci.2016.04.036

29. S. Kallip, A.C. Bastos, K.A. Yasakau, M.L. Zheludkevich and M.G.S. Ferreira, Synergistic corrosion inhibition on galvanically coupled metallic materials, Electrochem. Commun., 2012, 20, 101-104. doi: 10.1016/j.elecom.2012.04.007

30. L.B. Coelho, D. Cossement and M.-G. Olivier, Benzotriazole and cerium chloride as corrosion inhibitors for AA2024-T3: An EIS investigation supported by SVET and ToFSIMS analysis, Corros. Sci., 2018, 130, 177-189. doi: 10.1016/j.corsci.2017.11.004

31. S.V. Oleynik, Yu.I. Kuznetsov, Yu.A. Kuzenkov and Yu.B. Makarychev, Khimicheskoye oksidirovaniye splava D16 v shchelochnykh rastvorakh (Chemical oxidation of D16 alloy in alkaline solutions, Korroz.: Mater., Zashch. (Corrosion: Materials, Protection), 2007, no. 3, 28-32 (in Russian).

32. Yu.A. Kuzenkov, S.V. Oleynik and L.F. Trubetskaya, Beskhromatnyye konversionnye pokrytiya na alyuminiyevom splave V95 (Chromate-free conversion coatings on B95 aluminum alloy), Korroz.: Mater., Zashch. (Corrosion: Materials, Protection), 2009, no. 4, 36-39 (in Russian).

33. Yu.M. Zimina, Yu.A. Kuzenkov and S.V. Oleynik, Zashchitnyye konversionnyye pokrytiya IFKhANAL na alyuminiyevykh splavakh (IFHANAL protective conversion coatings on aluminum alloys), Korroz.: Mater., Zashch. (Corrosion: Materials, Protection), 2010, no. 7, 36-39 (in Russian).

34. Yu.A. Kuzenkov, S.V. Oleynik, S.A. Karimova and T.G. Pavlovskaya, Beskhromatnyye konversionnyye pokrytiya na alyuminiyevom splave 1370 (Chromatefree conversion coatings on 1370 aluminum alloy), Korroz.: Mater., Zashch. (Corrosion: Materials, Protection), 2011, no. 10, 42-47 (in Russian).

35. Yu.A. Kuzenkov, S.V. Oleinik and A.S. Koryakin, Ingibirovaniye beskhromatnykh konversionnykh pokrytiy IFKhANAL-3 na alyuminiyevom splave V95T2 (Inhibition of chromate-free conversion coatings IFKhANAL-3 on aluminum alloy V95T2), Korroz.: Mater., Zashch. (Corrosion: Materials, Protection), 2016, no. 9, 34-39 (in Russian).

36. Yu.A. Kuzenkov, S.V. Oleinik and A.S. Koryakin, Ingibirovaniye beskhromatnykh konversionnykh pokrytiy IFKhANAL-3 na alyuminiyevom splave V95T2 (Inhibition of chromate-free conversion coatings IFKhANAL-3 on aluminum alloy V95T2), Korroz.: Mater., Zashch. (Corrosion: Materials, Protection), 2018, no. 1, 35-40 (in Russian). 
37. A.S. Koriakin, Yu.A. Kuzenkov and S.V. Oleynik, The protective properties of conversion coatings on 1424 alloy upon oxidation under various conditions, Int. J. Corros. Scale Inhib., 2019, 8, no. 2, 268-274. doi: 10.17675/2305-6894-2019-8-2-8

38. G.I. Youssef, A.E. El Meleigy, L.A. Khorshed, A. Attia and E.A. Ashour, Inhibitive effect of benzotriazole on the corrosion and corrosion fatigue of $\alpha-\mathrm{Al}$ bronze alloy in LiBr solution, Mater. Corros., 2018, 69, 1827-1836. doi: 10.1002/maco.201810218

39. C.J. Brinker and G.W. Scherer, sol-gel Science: The Physics and Chemistry of sol-gel Processing, 1990, Academic Press, 908.

40. M. Kadkhodie, A. Shanaghi and H. Moradi, Improving of Corrosion Behavior of Al 7075 by Applied Titania-Benzotriazole Nanostructured Coating with Sol Gel Method, Prot. Met. Phys. Chem. Surf., 2017, 53, no. 6, 1040-1049. doi: 10.1134/S2070205117060120

41. H. Yang and W.J. van Ooij, Plasma Deposition of Polymeric Thin Films on Organic Corrosion-Inhibiting Paint Pigments: A Novel Method to Achieve Slow Release, Plasmas Polym., 2003, 8, no. 4, 297-323. doi: 10.1023/A:1026389311431

42. D.G. Shchukin, M. Zheludkevich, K. Yasakau, S. Lamaka, M.G.S. Ferreira and H. Möhwald, Layer-by-Layer Assembled Nanocontainers for Self-Healing Corrosion Protection, Adv. Mater., 2006, 18, 1672-1678. doi: 10.1002/adma.200502053

43. G. Decher, J.D. Hong and J. Schmitt, The buildup of ultrathin multilayer films by a selfassembly process: III. Consecutively alternating adsorption of anionic and cationic polyelectrolytes on charged surfaces, Thin Solid Films, 1992, 210-211, 831-835. doi: 10.1016/0040-6090(92)90417-A

44. M.L. Zheludkevich, D.G. Shchukin, K.A. Yasakau, H. Möhwald and M.G.S. Ferreira, Anticorrosion Coatings with Self-Healing Effect Based on Nanocontainers Impregnated with Corrosion Inhibitor, Chem. Mater., 2007, 19, 402-411. doi: 10.1021/cm062066k

45. D. Raps, T. Hack, J. Weh, M.L. Zheludkevich, A.C. Bastos, M.G.S. Ferreira and O. Nuyken, Electrochemical study of inhibitor-containing organic-inorganic hybrid coatings on AA2024, Corros. Sci., 2009, 51, 1012-1021. doi: 10.1016/j.corsci.2009.02.018

46. D. Borisova, H. Möhwald and D.G. Shchukin, Mesoporous Silica Nanoparticles for Active Corrosion Protection, ACS Nano, 2011, 5, 1939-1946. doi: 10.1021/nn102871v

47. H. Möhwald and D.G. Shchukin, Surface-Engineered Nanocontainers for Entrapment of Corrosion Inhibitors, Adv. Funct. Mater., 2007, 17, 1451-1458. doi: 10.1002/adfm.200601226

48. Yu.M. Lvov, D.G. Shchukin, H. Möhwald and R.R. Price, Halloysite Clay Nanotubes for Controlled Release of Protective Agents, ACS Nano, 2008, 2, no. 5, 814-820. doi: $10.1021 / \mathrm{nn} 800259 \mathrm{q}$

49. E. Abdullayev, R. Price, D. Shchukin and Yu. Lvov, Halloysite Tubes as Nanocontainers for Anticorrosion Coating with Benzotriazole, ACS Appl. Mater. Interfaces, 2009, 1, no. 7, 1437-1443. doi: $10.1021 / \mathrm{am} 9002028$ 
50. G. Williams and H.N. McMurray, Anion-Exchange Inhibition of Filiform Corrosion on Organic Coated AA2024-T3 Aluminum Alloy by Hydrotalcite-Like Pigments, Electrochem. Solid-State Lett., 2003, 6, no. 3, B9-B11. doi: 10.1149/1.1539771

51. G. Williams and H.N. McMurray, Inhibition of Filiform Corrosion on Polymer Coated AA2024-T3 by Hydrotalcite-Like Pigments Incorporating Organic Anions, Electrochem. Solid-State Lett., 2004, 7, no. 5, B13-B15. doi: 10.1149/1.1691529

52. M.L. Zheludkevich, J. Tedim and M.G.S. Ferreira, "Smart" coatings for active corrosion protection based on multi-functional micro and nanocontainers, Electrochim. Acta, 2012, 82, 314-323. doi: 10.1016/j.electacta.2012.04.095

53. M. Serdechnova, S. Kallip, M.G.S. Ferreira and M.L. Zheludkevich, Active self-healing coating for galvanically coupled multi-material assemblies, Electrochem. Commun., 2014, 41, 51-54. doi: 10.1016/j.elecom.2014.01.023

54. M. Serdechnova, A.N. Salak, F.S. Barbosa, D.E.L. Vieira, J. Tedim, M.L. Zheludkevich and M.G.S. Ferreira, Interlayer intercalation and arrangement of 2mercaptobenzothiazolate and 1,2,3-benzotriazolate anions in layered double hydroxides: In situ X-ray diffraction study, J. Solid State Chem., 2016, 233, 158-165. doi: 10.1016/j.jssc.2015.10.023

55. I. Recloux, M. Mouanga, M.-E. Druart, Y. Paint and M.-G. Olivier, Silica mesoporous thin films as containers for benzotriazole for corrosion protection of 2024 aluminum alloys, Appl. Surf. Sci., 2015, 346, 124-133. doi: 10.1016/j.apsusc.2015.03.191

56. I. Recloux, Y. Gonzalez-Garcia, M.E. Druart, F. Khelifa, P. Dubois, J.M.C. Mol and M.-G. Olivier, Active and passive protection of AA2024-T3 by a hybrid inhibitor doped mesoporous sol-gel and top coating system, Surf. Coat. Technol., 2016, 303, 352-361. doi: 10.1016/j.surfcoat.2015.11.002

57. S.M. Dezfuli, A. Shanaghi and S. Baghshahi, Effect of $\mathrm{Al}_{2} \mathrm{O}_{3}$ and $\mathrm{Y}_{2} \mathrm{O}_{3}$ on the corrosion behavior of $\mathrm{ZrO}_{2}$ - benzotriazole nanostructured coatings applied on AA 2024 via a solgel method, Int. J. Miner., Metall. Mater., 2018, 25, no. 11, 1344-1353. doi: 10.1007/s12613-018-1688-2

58. S. Lamaka, M.L. Zheludkevich, K.A. Yasakau, M.F. Montemor, P. Cecilio and M.G.S. Ferreira, $\mathrm{TiO}_{\mathrm{x}}$ self-assembled networks prepared by templating approach as nanostructured reservoirs for self-healing anticorrosion pre-treatments, Electrochem. Commun., 2006, 8, 421-428. doi: 10.1016/j.elecom.2005.12.019

59. K.A. Yasakau, M.L. Zheludkevich, O.V. Karavai and M.G.S. Ferreira, Influence of inhibitor addition on the corrosion protection performance of sol-gel coatings on AA2024, Prog. Org. Coat., 2008, 63, 352-361. doi: 10.1016/j.porgcoat.2007.12.002

60. M.S. Sharifiyan, A. Shanaghi, H. Moradi and P.K. Chu, Effects of high concentration of benzotriazole on corrosion behavior of nanostructured titania-alumina composite coating deposited on Al 2024 by sol-gel method, Surf. Coat. Technol., 2017, 321, 36-44. doi: 10.1016/j.surfcoat.2017.04.041

61. A. Shanaghi and M. Kadkhodaie, Investigation of high concentration of benzotriazole on corrosion behavior of Titania-Benzotriazole hybrid nanostructured coating applied 
on Al 7075 by the sol-gel method, Corros. Eng., Sci. Technol., 2017, 52, 332-342. doi: 10.1080/1478422X.2017.1288353

62. M. Farahani, H. Yousefnia, Z.S. Seyedraoufi and Y. Shajari, The effect of benzotriazole gradual change on the corrosion performance of nanocomposite multilayer self-healing coating based on Titania-Alumina-Benzotriazole on AA7075, Ceram. Int., 2019, 45, 16584-16590. doi: 10.1016/j.ceramint.2019.05.197

63. A.R. Simbar, A. Shanaghi, H. Moradi and P.K. Chu, Corrosion behavior of functionally graded and self-healing nanostructured $\mathrm{TiO}_{2}-\mathrm{Al}_{2} \mathrm{O}_{3}$ - Benzotriazole coatings deposited on AA 2024-T3 by the sol-gel method, Mater. Chem. Phys., 2020, 240, 122233. doi: 10.1016/j.matchemphys.2019.122233

64. H.A. El-Dahan, T.Y. Soror and R.M. El-Sherif, Studies on the inhibition of aluminum dissolution by hexamine-halide blends: Part I. Weight loss, open circuit potential and polarization measurements, Mater. Chem. Phys., 2005, 89, 260-267. doi: 10.1016/j.matchemphys.2004.07.024

65. G.K. Gomma and M.H. Wahdan, Schiff bases as corrosion inhibitors for aluminum in hydrochloric acid, Mater. Chem. Phys., 1995, 39, 209-213. doi: 10.1016/02540584(94)01436-K

66. G. Bereket and A. Yurt, The inhibition effect of amino acids and hydroxycarboxylic acids on pitting corrosion of aluminum alloy 7075, Corros. Sci., 2001, 43, 1179-1195. doi: $10.1016 / \mathrm{S} 0010-938 \mathrm{X}(00) 00135-9$

67. K.F. Khaled and M.M. Al-Qahtani, The inhibitive effect of some tetrazole derivatives towards Al corrosion in acid solutions: chemical electrochemical and theoretical studies, Mater. Chem. Phys., 2009, 113, 150-158. doi: 10.1016/j.matchemphys.2008.07.060

68. A.N. Önal and A.A. Aksüt, Corrosion inhibition of aluminum alloys by tolyltriazole in chloride solutions, Anti-Corros. Methods Mater., 2000, 47, no. 6, 339-349. doi: 10.1108/00035590010354177

69. G. Bereket and A. Pinarbaşi, Electrochemical thermodynamic and kinetic studies of the behavior of aluminum in hydrochloric acid containing various benzotriazole derivatives, Corros. Eng., Sci. Technol., 2004, 39, no. 4, 308-312. doi: 10.1179/174327804X13136

70. M.J. Peyor and D.S. Keir, The Nature of Aluminum as a Cathode, J. Electrochem. Soc., 1955, 102, no. 10, 605-607. doi: $10.1149 / 1.2429921$

71. B. Ramezanzadeh, M. Mehdipour, S.Y. Arman and M. Ramezanzadeh, An electrochemical investigation of azole derivative on aluminum in $0.25 \mathrm{M} \mathrm{HCl}$ solution using EN and EIS techniques, Anti-Corros. Methods Mater., 2017, 64, no. 1, 10-22. doi: 10.1108/ACMM-02-2015-1507

72. S. Kaya, P. Banerjee, S.Kr. Saha, B. Tüzün and C. Kaya, Theoretical evaluation of some benzotriazole and phospono derivatives as aluminum corrosion inhibitors: DFT and molecular dynamics simulation approaches, RSC Adv., 2016, 6, 74550-74559. doi: 10.1039/c6ra14548e 